measure for a then-unidentified and, hence, not directly measurable hepatitis virus. Since the hepatitis $\mathrm{C}$ virus was identified and a specific test developed to detect its presence, the value of the ALT test has been called into question.

"AL'T testing as currently used results in the loss of thousands of healthy blood donors as well as unnecessary concerns about liver disease," says Jane Desforges of the New England Medical Center in Boston, who chaired the panel. Perhaps as many as 200,000 units of blood are rejected needlessly each year on the basis of ALT test results, the panel estimates. Moreover, donors who are informed that their blood is being rejected on this basis may undergo follow-up testing beyond what is nceded and may also be wrongly deemed ineligible for donating blood. The panel's report concludes that continued testing "will be rarely, if ever, helpful."

Although the panel unequivocally recommended abandoning the ALT test, it concluded that two other outmoded tests on blood samples, one for detecting antibodies to the hepatitis $\mathrm{B}$ virus core antigen (anti-HBc) and the other for syphilis, continue to be routinely conducted.

Like the ALT test, the anti-HBc screening test came into wide use about a decade ago when blood banks needed a means for determining whether the non- $A$, non-B hepatitis virus might be present as a contaminant. Now that the direct test for hepatitis $C$ is available, this older indirect test has little value for that once-important purpose. However, the panel concluded, such testing continues to "reduce the risk of hepatitis B infections from blood" and also "is useful in identifying a small number of donors whose blood is infectious for HIV but who do not yet test positive in HIV tests."

The panel's recommendations on syphilis testing are more problematic. "The number of syphilis cases from blood transfusions is negligible," Desforges admits. "The problem is that we've been testing for syphilis in blood for 50 years. Our recommendation is that we keep the test for now but study the biology of Treponema pallidum in stored blood and platelets to see whether it's really a hazard." The number of blood units that test positive for syphilis is very low, probably less than $0.1 \%$, and many of those are probably false-positive results, says panelist Jeffrey McCullough of the University of Minnesota Hospital in Minneapolis.

JEFFREY L. FoX Washington, $D C$

\title{
European drug evaluation agency opens for business
}

The European Agency for the Evaluation of Medicinal Products - Europe's longplanned equivalent of the US Food and Drug Administration (FDA) - has opened for business in London, England. Use of the new centralized evaluation and registration procedure, leading to a single marketing authorization valid throughout the European Union, will be compulsory for all new biotechnology drugs (medicines produced by recombinant methods). For all other products, however, companies can either opt for the centralized services of the new agency, or seek approval from the national regulatory agencies, with the understanding that approval in one country within the European Union will allow the drug to be marketed in all others.

The new agency seeks to ensure that uniform standards for evaluating the safety of new drugs are applied across all fifteen member states, replacing the current patchwork of national regulatory requirements. By streamlining pro-

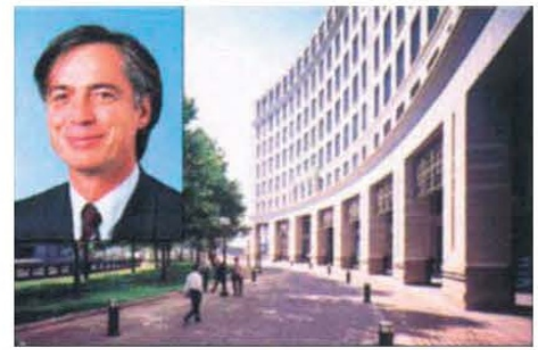

Sauer (inset), head of the new European Agency for the Evaluation nal Products, which will be responsible for the scientific assessment of applications.

In contrast to the FDA, however, the new European agency will not build up a large central bureaucracy or research facilities - total staff numbers are only planned to grow to 250 over the next five years, 50 of whom will be scientists but will draw directly on facilities that already exist in member states of the European Union. "To that extent, we do not intend to create an FDA for Europe as a tolally centralized agency," says Sauer. "We have used a totally different approach, which is to use the [national] agencies that already exist to get the best scientific evaluation possible."

To assist in this task, a list of 1,600 individuals has been drawn up who will help in the evalua tion of new products by serving on multinational and multidisciplinary teams coordinated by the medicinal products committee and its equivalent for veterinary products. In addition, a computer-based netcedures, the agency aims to provide regulatory approval for new drugs "within $\mathbf{3 0 0}$ days"; this would be considerably shorter than the review period in some countries which can take up to several years.

According to its executive director, 47year-old French pharmacist Fernand Sauer, one of the reasons for establishing the agency is that many countries lack the expertise to evaluate the safety of biotechnology drugs. But he also admits that there has been pressure from industry for a more centralized procedure. The concern is that local opposition in countries such as Germany or Denmark is also seen as an obstacle to the production and marketing of biotechnology products that are accepted elsewhere.

Furthermore, according to Sauer, one of the means of achieving such uniform standards will be to make the registration of new drugs "more scientific". lor example, the representation of clinicians, rather than administrators, has been increased on the Committee for Proprietary Medici- work is being set up with the backing of the European Commission's Joint Research Centre at Ispra in Italy to ensure the rapid transmission of data warning of potential problems with drugs that have already been marketed.

But the agency is already having to work with a much tighter budget than it would like. For 1995, the budget is expected to be about Ecu 20 million (US $\$ 24.5$ million), although the final figure will depend on the amount raised in 'user fees'. Having initially planned to charge companies Ecu200,000 $(\$ 246,800)$ for each new drug evaluated, the agency has been forced by political pressure from the European commission - concerned that industry may be reluctant to pay the higher charge - to reduce its fee to Ecu140,000 $(\$ 172,760)$. While welcoming in principle the new procedures, many companies still remain wary at the potential for adding a new layer of bureaucracy.

DAVID DICKSON London 